University of Washington Tacoma

UW Tacoma Digital Commons

SIAS Faculty Publications

School of Interdisciplinary Arts and Sciences

$7-2004$

\title{
Dominance in College Football and the Role of Scholarship Restrictions
}

Katie Baird

University of Washington Tacoma, kebaird@uw.edu

Follow this and additional works at: https://digitalcommons.tacoma.uw.edu/ias_pub

Part of the Economics Commons, and the Sports Studies Commons

\section{Recommended Citation}

Baird, Katie, "Dominance in College Football and the Role of Scholarship Restrictions" (2004). SIAS Faculty Publications. 32. https://digitalcommons.tacoma.uw.edu/ias_pub/32

This Article is brought to you for free and open access by the School of Interdisciplinary Arts and Sciences at UW Tacoma Digital Commons. It has been accepted for inclusion in SIAS Faculty Publications by an authorized administrator of UW Tacoma Digital Commons. 


\title{
Dominance in College Football and the Role of Scholarship Restrictions
}

\author{
Katherine Baird \\ University of Washington, Tacoma
}

\begin{abstract}
This article examines the relationship between player compensation in college football and competitive balance on the field. It shows that National Collegiate Athletic Association rule changes restricting football-player compensation are not associated with an improvement in football's competitive balance. Although college football is marginally more balanced than professional sports in any given year, an examination of cumulative records spanning numerous seasons proves college football to be as unbalanced as professional sports. The movement toward reducing player compensation, coincident with an increasing value to player talent, raises issues over how the financial gain from college football talent should be used. The significant degree of talent (and financial) imbalance among college football teams suggests that more attention should be paid to the determinants of talent distribution in college football.
\end{abstract}

At many American universities intercollegiate football produces significant resources for school athletic departments. In 2002, for example, football provided the University of Washington with a net of \$15.8 million (P. King, personal communication, December 23, 2002) and Ohio State with a net of \$20.3 million (Suggs, 2002). As researchers have long pointed out, the existence of such significant profits in college football can be largely attributed to National Collegiate Athletic Association (NCAA) regulations limiting player compensation. Without such regulations teams competing for players would bid up compensation levels, thereby reducing football profits by driving up expenses. Many reasons have been advanced for the current policy of restricting college players' pay; one of these is the need to maintain competitive balance among college teams (Fort, 2003). Whether restrictions on college-player compensation improve competitive balance is debatable. The relationship is important in that it bears both on the justification for restricting college-players' pay and on who should benefit from the financial rewards generated by college football. The presumed relationship also applies to formulations of remedies for alleviating competitive imbalances in college football.

The author is with Interdisciplinary Arts and Sciences, University of WashingtonTacoma, Tacoma, WA, 98402-3100. 
This article investigates the relationship between player compensation and competitive balance in college football. Theory, as well as empirical evidence on the relationship between the two, is ambiguous. The article examines this relationship by analyzing competitive balance in Division IA college football (hereafter college football) during the period 1985 to 2001 to see whether reductions in the number of scholarships given to football players during this period have improved competitive balance among college football teams. The degree of imbalance in college football is also examined.

The findings show that, in any one year, college football is somewhat more balanced than professional sports. Examining cumulative records spanning several seasons, however, reveals that college football rivals professional sports in its degree of competitive imbalance. Although perhaps not astounding to college football fans, the study reveals both the degree of imbalance and the significant differences in competitive balance that exist among different college football onferences. Unlike competitive balance in professional sports, this issue has received surprisingly little attention among sports analysts. The analysis presented here indicates that reductions in the number of football scholarships offered over this time period have had no discernible impact on competitive balance in college football. It thus supports claims made elsewhere with respect to professional sports, that redistributing a player's value to others will not improve balance (Butler, 1995; Fort, 2003; Maxcy, 2002; Rottenberg, 1956).

The article is divided into three sections. Section 1 provides a background on the issue of player compensation and competitive balance. Section 2 presents a statistical analysis of the relationship between recent reductions in player compensation and competitive balance; it shows that there is no evidence linking increased restrictions on pay with increased competitive balance. The analysis also reveals the extent of competitive imbalance in college football and the differences among various college football conferences. My conclusions are outlined in the third section.

\section{Background}

\section{Revenue and Player Restrictions}

It is well documented that certain college football and basketball teams net significant revenue for their institutions (Fort, 2003; Noll, 1991; Sheehan, 2000; Zimbalist, 1999). In fact, college football alone likely earns select educational institutions hundreds of millions of dollars per year (Witosky, 2002; Zimbalist). NCAA regulations play an important role in both the existence and distribution of these financial gains. Most importantly, NCAA regulations limit athletes' compensation to the nonmonetary benefits of tuition, books, and room and board. They also limit the number of "full-ride" scholarships that each school can offer. In football, NCAA regulations currently limit the annual number of full-ride scholarships to 85; before 1994 the NCAA allowed 95, and before 1988 it permitted 105 . 
Schools undoubtedly compete rigorously for prospective star football players. If the NCAA imposed no restrictions, universities would certainly use financial incentives of some sort to attract talented athletes because star football and basketball athletes can generate tremendous revenue for some schools (Brown, 1993, 1994; Fort, 2003; Noll, 1991). NCAA regulations are binding, as made obvious by the pervasiveness of NCAA sanctions against schools that attempt to get around player pay restrictions. Moreover, with the expenses of fielding a top football team growing over time, the pressure to circumvent restrictions has likewise increased. For example, between 1985 and 2001 the amount of football revenue generated by the highest earning school team grew from $\$ 10.7$ million to $\$ 66.3$ million (Witosky, 2002; Zimbalist, 1999, p. 160). The University of Washington's football revenue, which is more typical of a top football team's revenue growth, more than doubled between 1987 and 2001 (P. King, personal communication, December 23, 2002). Given these financial trends, it is not surprising that, during the past 40 years, the number of NCAA investigations into possible infractions of its regulations has steadily increased (Depken \& Wilson, 2002; Zimbalist).

\section{Player Pay Restrictions and Competitive Balance.}

There are a variety of justifications for NCAA player-compensation regulations. The regulations, it is argued, improve competitive balance, maintain the amateur nature of college sports, provide needed funds for schools' athletic programs, and make coaches more mindful of the academic potential of prospective football recruits (Fort, 2003; P. Parker, personal communication, January 27, 2003). The 2002-2003 NCAA manual states that NCAA regulations are designed to advance 1 or more of 16 principles; one of these is the "principle of competitive equity" whereby the NCAA "shall promote opportunity for equity in competition to assure that individual student-athletes and institutions will not be prevented unfairly from achieving the benefits inherent in participation in intercollegiate athletics" (NCAA, 2002, p. 5). Restricting pay is also said to be necessary to maintain the special amateur nature of college football. Because school athletic programs rarely break even, the money generated by football is an important source of revenue for many athletic departments. Finally, the NCAA argues that scholarship restrictions, particularly limits on a coach's ability to transfer the scholarship of a player who drops out to another player, make coaches more mindful of the academic potential of their recruits. This was the official rationale for the NCAA's decision to reduce the number of football scholarships in 1993 (P. Parker, personal communication, January 27, 2003).

Player pay restrictions are commonly believed to promote competitive balance because fewer scholarships for football players will reduce the ability of better teams to entice the best football prospects to their schools. As a result, talent will be more evenly distributed throughout football conferences, allowing weaker schools to field more competitive teams. Scholarship limits are, thus, thought to help stop less wealthy teams from being "overpowered in the second half by big squads from rich football schools" (Byers, 1995, p. 227). 
The belief that unbridled competition for players would lead to large imbalances on the playing field is a widespread one because it is assumed that wealthier or more successful schools would outcompete other schools for star players. Jim Scherr, executive director of USA Wrestling, is quoted as saying: "It's time to scale down to, say, 70 scholarships. ... If football scholarships were decreased ... more of college football's have-nots would get a chance to compete with the behemoths in Division IA, which would make for more interesting games"1 Such a belief in the consequences of reduced scholarships is common among both college and NCAA officials (Fort, 2003, p. 440).

Theory, however, is ambiguous about the consequences of greater competition for college football players in terms of talent distribution (Fort \& Quirk, 1999). If pay restrictions act as a salary cap, they might improve balance by reducing the role of differential football revenue on the distribution of talent. It is certainly true that college football teams in the same conferences generate vastly different revenue for their schools. In the PAC-10 conference, for example, the University of Washington's football team brought in \$26.6 million in 2001, whereas Washington State's team brought in $\$ 7.1$ million; in the SEC conference, Arkansas topped the nation by bringing in $\$ 66.3$ million, whereas Mississippi State's football team brought in only $\$ 9.2$ million (Witosky, 2002).

On the other hand, equal spending on football players by no means assures equal spending on football per se. Schools could compete for players by differentially investing in coaches, facilities, recruitment, training, tutoring, and other factors that influence a player's choice of school. For example, in 2001 twenty-two colleges paid their football coaches salaries in excess of $\$ 1$ million per year; these salaries generally ranged from 4-8\% of the team's total football revenue (Witosky, 2002), and only schools with high-revenue programs could justify paying them. Such high salaries reflect the fact that many football players, motivated by expected future incomes, want to play for the teams and coaches that give them the best chance of making the pros. As such, small changes in current "earnings" could have little effect on players' decisions about whom to play for.

High expenditures on coaches' salaries by top-revenue teams suggest there might be, as Fort (2003) argues, a college version of Rottenberg's invariance principle. Rottenberg (1956) argued that, in professional sports, the location of player talent should be invariant with restrictions on player pay. This theory, which has received considerable empirical support in the literature, is now referred to as the Rottenberg invariance principle. ${ }^{2}$ In college football, top-revenue teams might lure the best talent, not by paying them (which they would if they could), but by investing in the resources that are most valuable to players - coaches and facilities that improve their odds of making the pros and nonmonetary benefits, such as travel accommodations.

Although the invariance principle suggests that player pay restrictions in college football will have no effect on competitive balance, some argue that these restrictions could actually hinder weaker teams, thereby harming competitive balance. With limited ability to compensate athletes, losing teams and weak 
conferences could be disadvantaged by NCAA regulations restricting player compensation and, hence, disadvantaged in the competition for wins and revenue.

\section{Previous Research}

The effect of NCAA regulations on outcomes in college sports has long been of interest to sports analysts. Many argue that the NCAA acts as a cartel to restrict competition and output, thereby increasing the financial gains to schools (Becker, 1985; Fleisher, Goff, \& Tollison, 1990; Koch, 1983; Noll, 1991); some further argue that these regulations reduce competitive balance (Eckard, 1998).

Researchers have examined justifications of NCAA regulations through empirical studies of the relationship between NCAA regulations and outcomes such as rents derived from players and competitive balance on the field. Brown $(1993,1994)$ and Leonard and Prinzinger (1984) examined the value of star players to colleges; their analyses showed that star basketball and football players during the 1980s could bring hundreds of thousands of dollars per year to a school. Today the amount is certainly much higher. Fort (2003), for example, estimates that quarterback Ryan Leaf brought at least \$2-3 million to Washington State University in 1998. Anecdotally, in 2001, the Ohio State football team netted (after all football expenses) \$20.3 million for its athletic department (Suggs, 2002). Dividing this amount by a squad of 100 players implies that the average amount brought in by each football player, in excess of all football costs (including their own scholarships), was $\$ 203,000$.

In one of the earliest studies examining the relationship between NCAA regulations and competitive balance, Fleisher et al. (1990) showed that NCAA investigations of illegal practices disproportionately fall on up-and-coming teams; they argued that NCAA sanctions make it harder for weaker teams to compete, thus harming balance by protecting stronger teams from competition. Evidence in Eckard (1998) supports this hypothesis; he argues that, since 1952, the NCAA's enforcement of its regulations had resulted in a decrease in competitive balance in college football. In Depken and Wilson's (2002) examination of the impact of NCAA probations and investigations on competitive balance in college football, they found that NCAA sanctions have had an ambiguous effect on football's competitive balance: Although sanctions seem to fall disproportionately on weaker teams, thereby reducing balance, they might also improve balance by discouraging cheating among better teams.

Bennett and Fizel (1995) examined the claim that NCAA control over football telecasts was necessary for maintaining balance among teams. Before 1985, the NCAA maintained complete control over college football telecasts. The NCAA claimed that this authority was necessary to assure a more even distribution of team exposure and, hence, of recruitment advantage and team balance. After the Supreme Court's 1984 decision in National Collegiate Athletic Association v. Board of Regents of the University of Oklahoma and University of Georgia Athletic Association, in which it was found that the NCAA's telecast monopoly violated the Sherman Antitrust Act, Bennett and Fizel showed that competitive balance in 
football remained the same, contrary to the effect predicted in the NCAA's arguments.

Sutter and Winkler (2003) looked at the role of scholarship restrictions on competitive balance in college football. Their findings, that scholarship restrictions have little to no effect on competitive balance, support Rottenberg's invariance principle. Their study, however, was largely based on an examination of overall rather than conference win-loss records. As will be discussed later in the article, conference records are a better indicator of competitive balance than are overall records.

In short, little evidence supports the claim that NCAA regulations help level the playing field; at best they appear to have had a very limited effect, and, at worst, they have served to strengthen the position of the dominant teams. An opportunity to further explore the effect of NCAA player pay regulations on competitive balance is presented by recent changes in NCAA regulations concerning player scholarships. In 1993 the NCAA decreased the number of scholarships that Division IA teams could provide their football players from 95 to 85 ; this followed a decision 5 years earlier that reduced the number of scholarships from 105 to 95 . Because this is the main form of immediate compensation that schools give to their football players, a 10-plus percent reduction during a period of rising college football revenue should have a noticeable effect on competition, if indeed the NCAA compensation regulations affect competition on the field at all. The current study, thus, extends the work of Eckard (1998) by disaggregating measures of competitive balance during the recent past, updates the period studied by Bennett and Fizel (1995) that ended in 1993, and supplements the work of Depken and Wilson (2002) and Bennett and Fizel by exclusively analyzing the effect of NCAA playercompensation regulations on competitive balance. Finally, it extends Sutter and Winkler's (2003) findings by examining conference rather than overall win-loss records.

\section{Competitive Balance in College Football}

Football is the most lucrative among all college sports, and the one in which NCAA regulations governing player compensation are the most binding. Do these regulations improve competitive balance? Without knowing what balance on the field would be like in the absence of NCAA player pay regulations, this is a difficult question to answer. What is known, however, is that football-player compensation for top teams, relative to the income they generate, has declined over time. As an example, during the last 10 years at the University of Washington, the revenue generated by football has increased $71 \%$ whereas compensation to players has increased by $43 \%$; this means that, during this time period, the share of gross football revenue being used to compensate athletes has declined at the University of Washington from $4.2 \%$ in 1991 to $3.5 \%$ in 2001 (P. King, personal communication, December 23, 2002). ${ }^{3}$ By comparison, in professional sports leagues in the US, players generally receive slightly more than half of all gross revenues. In 
addition, in the NFL, players receive roughly two-thirds of all revenue (Fort, 2003). This trend in college football is analogous to a successively more restrictive salary cap, which theoretically could improve balance if it permitted every team, regardless of revenue, to acquire top football talent.

\section{Measuring Competitive Balance}

To examine whether or not greater restrictions on player compensation improve competitive balance among college football teams, a definition of competitive balance is needed. The idea is simple: more balance means that the player talent pool is more equally distributed among teams, with the result that the distribution of wins in a league or conference should be relatively even. One approach to measuring the balance among teams is to treat a sports league (or conference) as an industry and to measure the extent of competition in the "industry" by way of measuring how concentrated the industry output is. One could quantify, for example, the concentration of a league output - such as total wins, revenue, points, or ticket sales - for a limited number of teams. Several researchers have used such an approach to measure the concentration of wins (Depken, 1999) or conference titles (Eckard, 1998) in college football. The concentration of revenue as an output in college football might also be of interest but is exceptionally difficult to measure because different institutions employ different accounting conventions (Sheehan, 2000).

A more common way to measure competitive balance in sports is to measure the spread in teams' win/loss $(\mathrm{W} / \mathrm{L})$ percentages within a league or conference and then to compare this spread with an ideal spread. This index was first advocated by Scully (1989); it is used in Quirk and Fort (1997) for professional leagues and in Fort (2003) and Bennett and Fizel (1995) for measuring competitive balance in college football. It is also the most common measure used throughout the literature on competitive balance in sports (e.g., Butler, 1995; Lee \& Fort, 2002; Szymanski, 2001). The index, the explanation of which follows, has intuitive appeal; it is also useful as a means of comparing competitive balance in college sports with that of professional sports because the index is used extensively in the literature on professional sports.

An actual standard deviation for a league is calculated by taking the difference between each team's W/L record and .500 , squaring this difference, then summing them by league or conference, and dividing by the number of teams. This is the variance in league W/L records, and the square root of this is the standard deviation in $\mathrm{W} / \mathrm{L}$ records for the league.

An idealized standard deviation is the theoretical standard deviation that would result if all teams were equal so that the outcome of any match was equivalent to the flipping of a coin. It is calculated for a league as 0.5 divided by the square route of $N$, where $N$ is the number of games per season played by each team in the league, and .5 is the expected winning record of each team.

The ratio of the actual to idealized standard deviation in $\mathrm{W} / \mathrm{L}$ records provides an index of competitive balance. A higher ratio indicates greater competitive 
imbalance. A ratio of 1 , or close to 1 , indicates perfect or near perfect balance. Quirk and Fort's (1997, pp. 247ff) detailed analysis of competitive balance in professional sports leagues during the 20th century reveals annual ratios typically between 1.5-2.5. Fort's (2003) analysis of the Pac-10 and Big 10 college football conferences reveals annual competitive balance ratios of between 1.2 and 2.0 between 1970 and 2000.

\section{Data}

To analyze competitive balance in Division IA college football, the W/L records of all Division IA teams were compiled for the period 1985-2001 (ties were excluded). Because teams are organized into conferences and typically play a majority of games in their conference, a distinction is made between conference and overall records. Based on these records, the ratio of actual standard deviation to idealized standard deviation for both conference records and overall records was calculated for each conference and for each year.

\section{Annual Measures of Competitive Balance}

Table 1 lists the ratios by conference and year for in-conference records only. As shown in Table 1, there is no obvious trend in competitive balance over this period. The year in which the (unweighted) average measure of conference competitive balance is best (lowest) was 1992, when the ratio of actual to ideal standard deviations was 1.33. The year in which the average conference balance is worst (highest) was 1988, when it was 1.53. Individual conferences show no obvious trend either. Comparing college football with professional sports, between 1970 and 1990 the annual measure of competitive balance in major-league baseball was 1.75 , in the NBA it was 2.53 , in the NFL it was 1.56 , and in the NHL it was 2.23 (Quirk \& Fort, 1997, p. 247).

Figure 1 shows the moving five-year average of annual measures of competitive balance for the major conferences over the study period: the Atlantic Coast Conference (ACC), the Big 12, the Big Ten, the Mid-American Conference (MAC), the Pac-10, and the Southeastern Conference (SEC). No overall trend is obvious, although an upward trend indicating a decrease in balance is detectable in the SEC and Pac- 10 over this time period.

These measures of competitive balance in college football show generally what Fort (2003) has shown for two college football conferences since 1970, and Bennett and Fizel (1995) show for major conferences during the 1980s: competitive balance in college football has remained quite stable over the last 40 years and is somewhat better than competitive balance in professional sports leagues. It also reveals that balance and trends vary somewhat by conference. Balance appears particularly poor in the Big 12 and $\mathrm{ACC}$, whereas historically it was better in the PAC-10. Such differences appear to be diminishing with time, however.

A statistical comparison of the pre-1994 era with the post-1994 era reveals that 1994 did not signal a significant change in competitive balance for the better. If anything, balance has become worse - statistically so in the case of the Pac-10, 


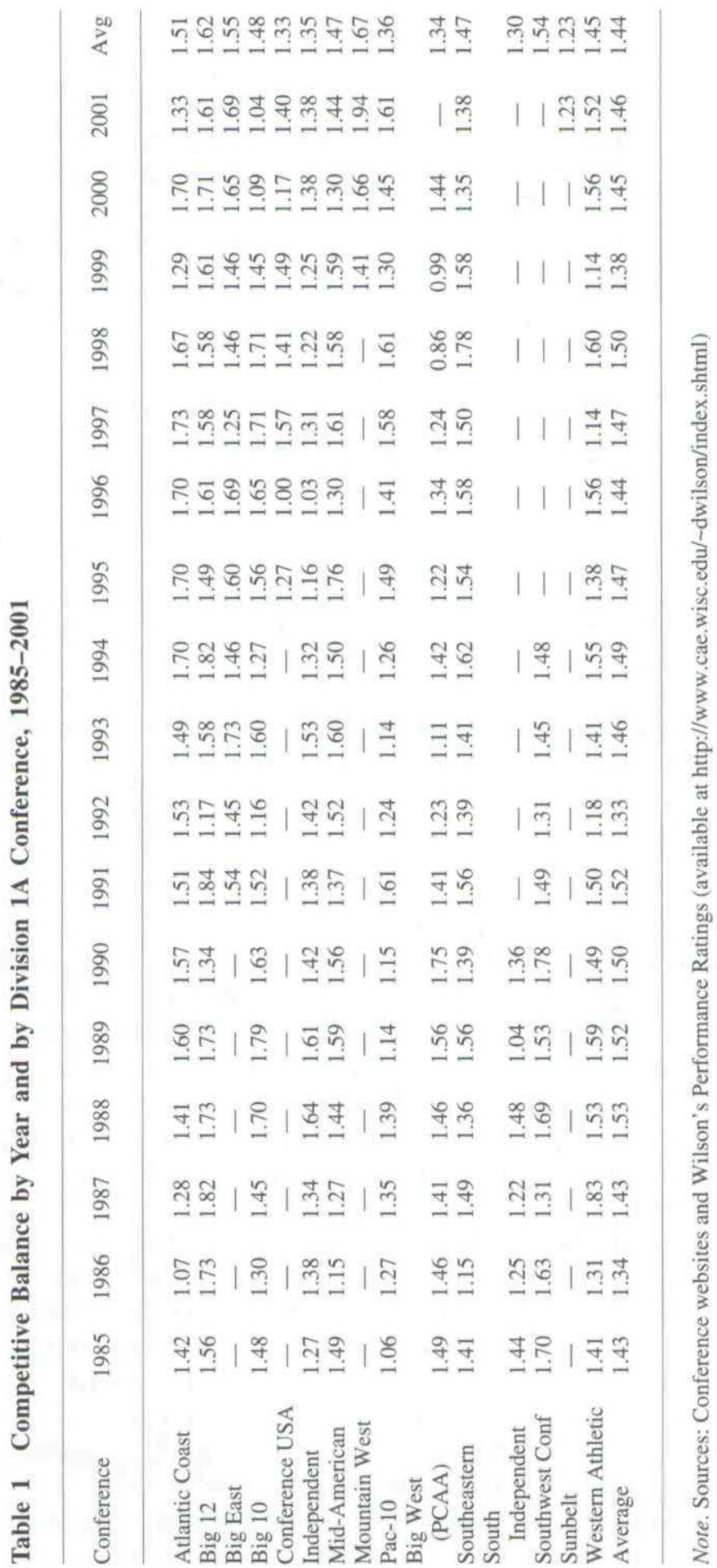




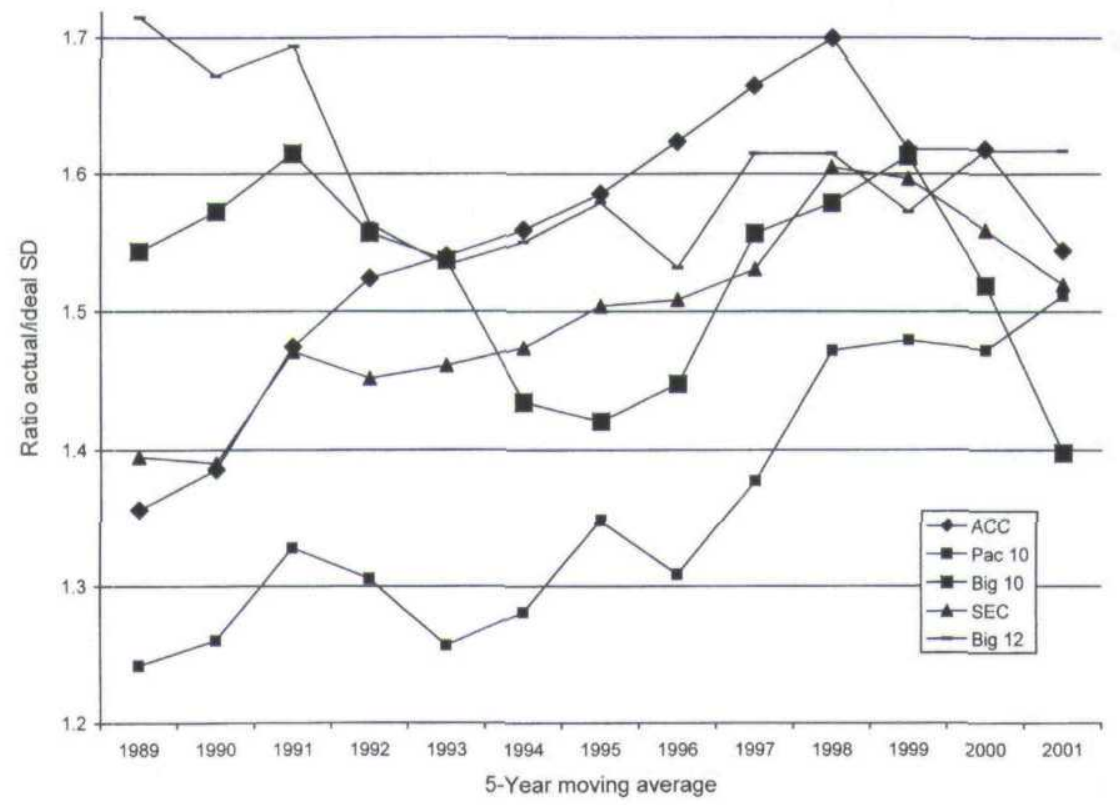

Figure 1 - Annual competitive balance indicators in division IA conferences: 19852001 (in-conference play).

SEC, and ACC (see Figure 2). Only in the now-nonexistent Big West (formerly the PCAA) was there a statistically significant improvement in competitive balance from pre-1994 to post-1994; the annual indicator dropped from an average of 1.43 (1985-1993) to 1.22 (1994-2001), a difference significant at the 5\% level of confidence. Figure 2 shows conference-by-conference comparisons during the two periods. This suggests preliminary support for Rottenberg's invariance principle: where talent goes (and thus competitive balance) is invariant with the degree of restrictions over player pay. No statistically significant change in competitive balance has occurred in college football since greater restrictions over paying athletes have been introduced.

The trends in balance just mentioned are based on intraconference play only. Competitive balance, however, among all Division IA football teams, as measured by the spread in overall records, is not too different from the spread that results from in-conference play. This is shown in Figure 3, which compares the unweighted average conference measure of competitive balance for in-conference play with a measure for overall play among all Division IA teams. For in-conference play during this period, the average varies from about 1.4 to 1.52 (based on three-year moving averages). For overall play, the average varies between 1.38 and 1.5.

It is surprising that overall college football records prove about as balanced (or imbalanced) as conference play; a common presumption is that college football 


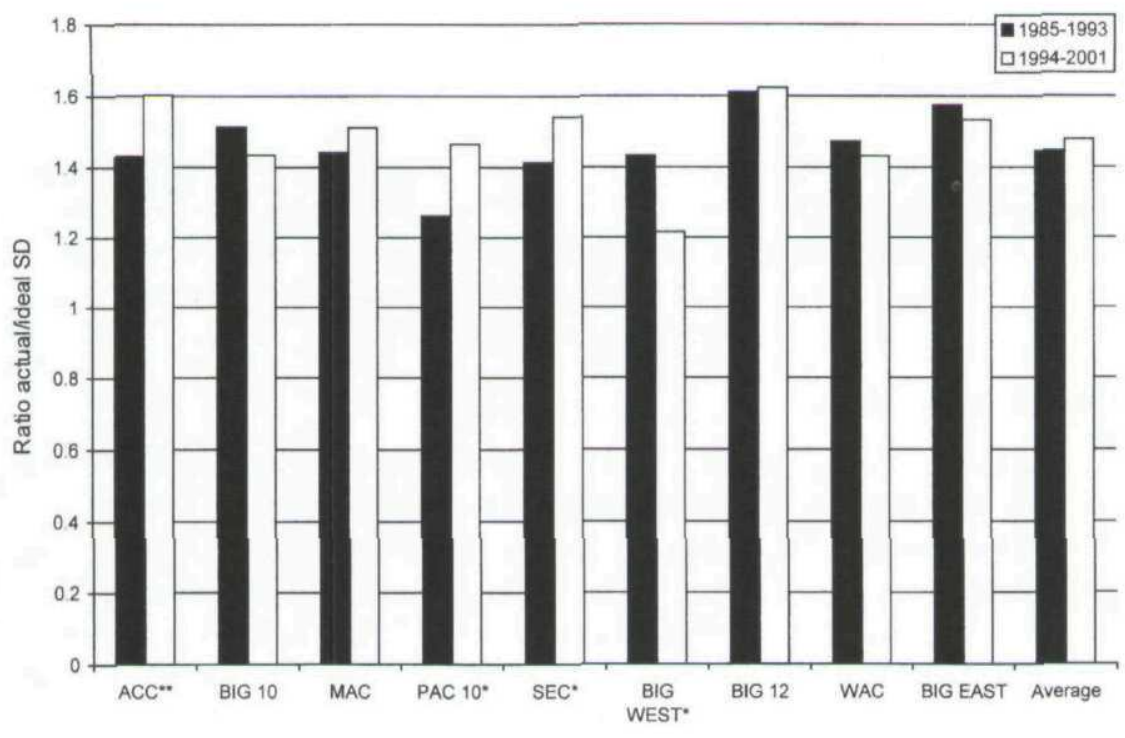

Conference

Figure 2 - Average annual competitive balance in division IA football by conference: 1985-1993 and 1994-2001. *Difference significant at the 5\% level of significance. **Difference significant at the $10 \%$ level of significance.

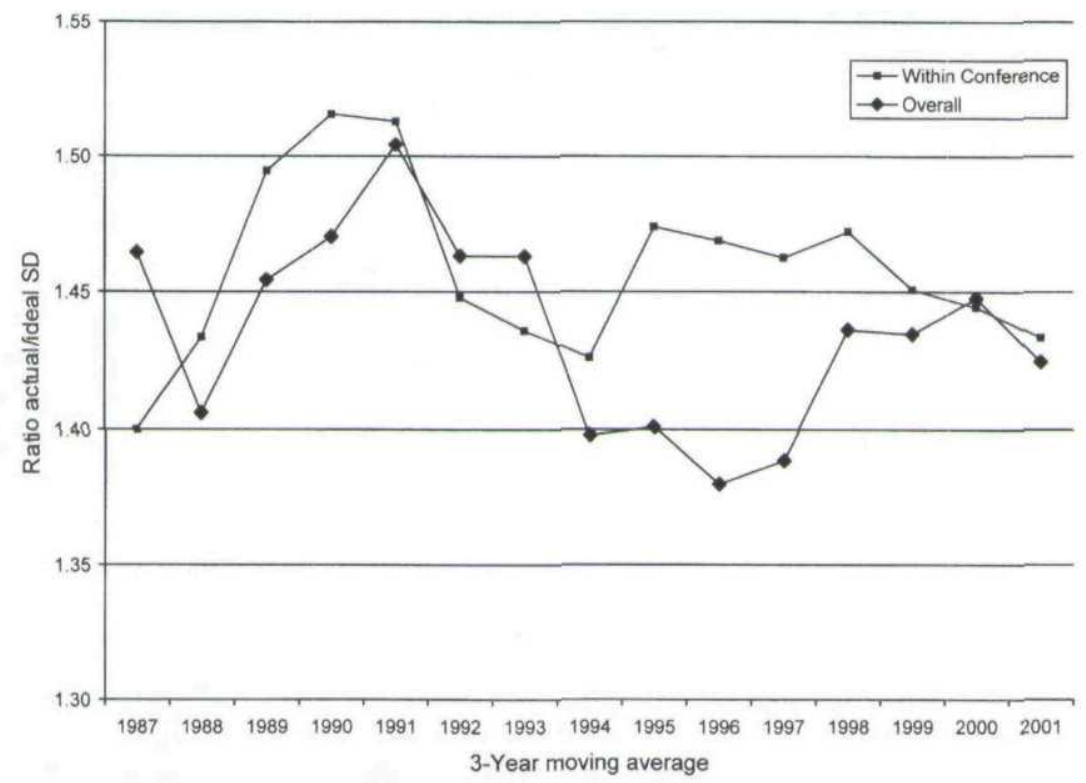

Figure 3-Annual competitive balance in division IA football 1985-2001: conference only vs. overall play. 
teams are more balanced in their conferences than they are in the nation at large. In college football, however, interconference team matchups are somewhat endogenous to past play: The best teams tend to play each other, as do the worst. Moreover, this tendency has intensified with the increasing financial gains to be made from exciting interconference matchups. For this reason an analysis of football's balance based on overall play is not particularly insightful: increasing (decreasing) balance could result from the arrangement of matchups rather than an improvement (decline) in the distribution of player talent.

\section{Team Dominance}

Competitive imbalance from year to year-some big winners, some big losers - is less important if individual team and conference fortunes vary by year. If good (and bad) seasons are equally distributed among teams in a conference, then, over the long term, no single team will dominate conference play, and balance could be considered quite good despite uneven outcomes in any one year. A separate question, then, is whether or not there has been a change in long-run domination in college football. One could examine long-term dominance by analyzing the concentration of conference championships, national rankings, or bowl appearances over time or by examining cumulative $\mathrm{W} / \mathrm{L}$ records.

To examine long-term dominance within each football conference, competitive balance indicators are calculated here based on teams' cumulative W/L records. This measure not only permits comparison with professional sports, but it also better captures persistent variation in teams' ability to win games.

Table 2 shows competitive-balance indicators by conference for the two periods under consideration. These indicators are based on cumulative $\mathrm{W} / \mathrm{L}$ record over the period 1985-1993, and 1994-2001. The time period with more generous football scholarships (105 and 95) is separated from the current, more stringent standard of 85. Did decreasing the permitted number of football scholarships coincide with a decrease in the domination of conferences by certain teams?

Immediately noteworthy in Table 2 is the extent of college football imbalance based on several years of cumulative records. This supports what most college football fans already know: some teams are perpetual winners, and some teams are perpetual losers. Over the period 1985-1993, the weighted average of all conference competitive balance indicators is 3.06, and over the period 1994-2001, it is 2.83. These numbers indicate significant and persistent differences among teams in each Division IA conference in their ability to win games.

As seen in Table 2, balance improved with fewer scholarships in some conferences, whereas, in others, it declined. From this longer term perspective, competitive balance appears best in the Pac-10 conference, where it was 2.6 in the 1985-1993 period and 2.21 in the 1994-2001 period. Average measures of conference dominance during the two periods, however, has neither changed significantly in magnitude (the change from 3.06 to 2.83 represents an $8 \%$ decrease) nor in a statistical sense (the difference is statistically insignificant even at the $80 \%$ level of confidence). Thus, based on longer term records, as well as annual records, 


\section{Table 2 Competitive Balance Indicators in Division 1A Football Conferences}

\begin{tabular}{|c|c|c|c|}
\hline Conference & Annual & 1985-1993 & 1994-2001 \\
\hline $\mathrm{ACC}$ & 1.51 & 5.36 & 3.51 \\
\hline Big 12 & 1.62 & 4.03 & 3.57 \\
\hline Big East & 1.55 & 2.10 & 3.68 \\
\hline Big 10 & 1.48 & 3.40 & 2.59 \\
\hline Mid-American & 1.35 & 2.23 & 3.12 \\
\hline Pac- 10 & 1.67 & 2.60 & 2.21 \\
\hline Southeastern Conf. & 1.34 & 2.57 & 3.27 \\
\hline Western Athletic & 1.23 & 3.01 & 2.78 \\
\hline Independent & 1.33 & 2.40 & 1.61 \\
\hline Big West (PCAA) & 1.36 & 2.81 & 1.87 \\
\hline Southwest Conf. & 1.30 & 3.28 & 1.48 \\
\hline Weighted average ${ }^{\mathrm{a}}$ & - & $3.06^{b}$ & $2.83^{b}$ \\
\hline
\end{tabular}

Note. Comparison is based on annual and cumulative records (1985-2001). ${ }^{2}$ Weights based on number of games played. ${ }^{b}$ Difference statistically insignificant at the $80 \%$ level of confidence.

the evidence here does not support the position that scholarship reductions improved balance on the playing field. It does support Rottenberg's invariance principle, however, that scholarship restrictions should have no effect on competitive balance.

The previous analysis also reveals that what is true in professional sports is also true in college football: the longer the time frame over which winning records are compiled, the more imbalanced play on the field is. To underscore this, competitive-balance indicators for college football were calculated based on cumulative conference records over the entire period from 1985-2001. Not surprisingly, competitive-balance indicators show that the balance is worse than for either of the shorter time periods. In all major conferences, competitive-balance indicators exceed 3.0, and the weighted average of all conferences is 3.8. This is summarized in Figure 4, which shows that in almost every conference, competitive balance worsens as the time frame over which team records are considered lengthens. This reveals both the degree of imbalance within conferences, as well as differences in the degree of competitive imbalance among conferences. Why balance is so much worse in some conferences than others is an important question because it bears on NCAA policies that attempt to improve fairness and the ability of any one school to build a winning team.

So how dominant are the best teams in college football? Table 3 shows the cumulative W/L percentage for select teams and conferences over the period 19852001 in order to compare long-run dominance in college football with long-run 


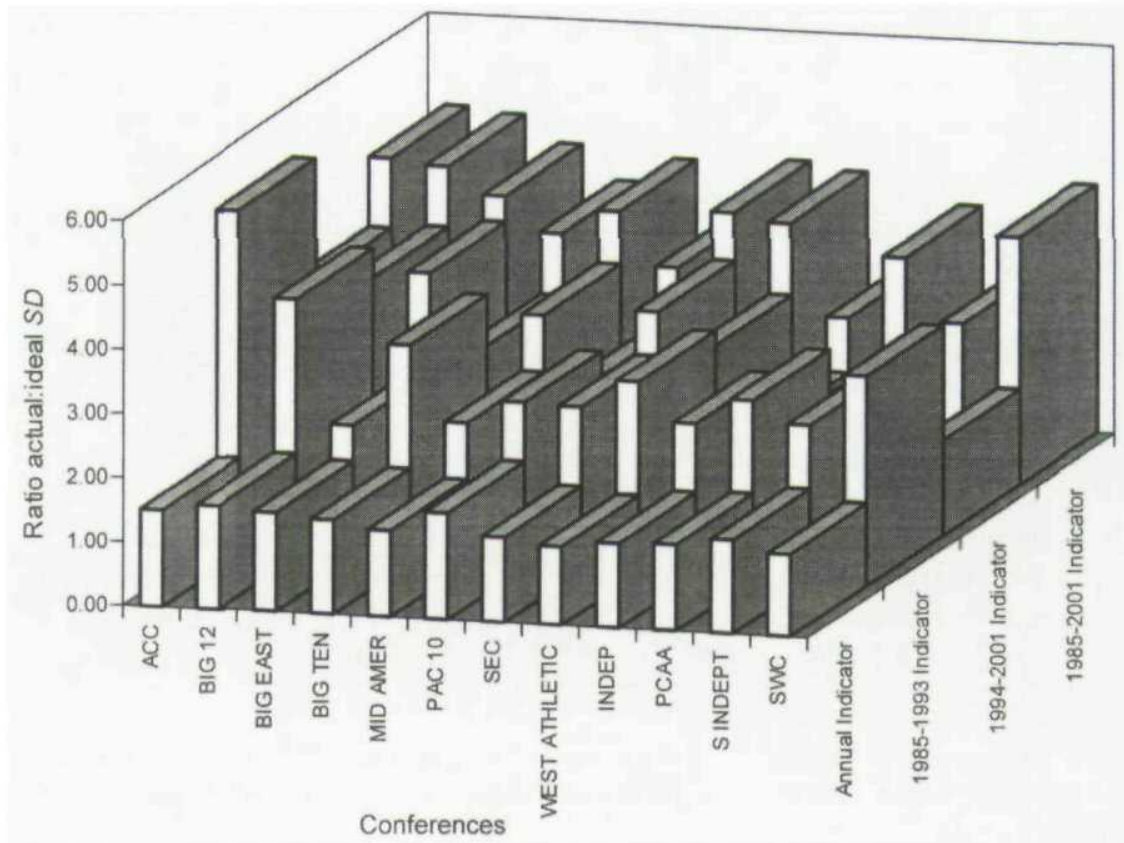

Figure 4 - Competitive balance in division IA football by conference: annual vs. cumulative records 1985-2001.

dominance in professional sports. The first column shows the number of standard deviations each team's record is above .500. It, thus, presents another measure of how far each team's record is from the assumption that each team is equally competitive. This calculation allows a comparison of long-run dominance in college football with that found in professional sports. Quirk and Fort (1997, pp. 264ff) calculate the number of standard deviations each professional team's lifetime record is above a .500 record.

With the exception of a few teams (e.g., the New York Yankees, the Boston Celtics, the Los Angeles Lakers, and the Montreal Canadians), team records lie between \pm 7 standard deviations of a .500 record, roughly the same range found in college football. In college football between 1985 and 2001, 22\% of cumulative team records are close to .500 (within \pm 1 standard deviation of a .500 record); this compares favorably with professional football, where only $13.3 \%$ of teams are this close to .500 , but unfavorably with professional basketball, where $34.6 \%$ of team lifetime records are near a .500 record.

On the other end, nearly one-third of college football teams' cumulative records are far from a .500 record (beyond \pm 3 standard deviations). This percentage is better than that of professional baseball, in which over $50 \%$ of baseball teams' are this far from .500, but is comparable to professional basketball, in which 
Table 3 Top Winning and Losing College Football Teams By Division IA Conference Cumulative Records: 1985-2001

$\begin{array}{cc}\text { \# of standard } & \text { Conference } \\ \text { deviations record } & \text { competitive } \\ \text { is over } .500^{\mathrm{a}} & \text { balance indicator }\end{array}$

\section{ACC}

Florida State

8.04

Virginia

3.01

Wake Forest

5.72

Duke

$-6.01$

Big 12

Nebraska

8.44

Colorado

4.96

Iowa

$-4.53$

Baylor

$-6.02$

Big East

Miami, FL

5.90

Syracuse

3.81

Rutgers

$-5.03$

Temple

$-6.04$

Big 10

Michigan

6.96

Ohio State

4.35

Minnesota

$-3.97$

Northwestern

$-4.39$

Mid-American

Marshall

4.74

Toledo

3.58

Buffalo

$-3.67$

Ohio

$-4.49$

\section{Pac-10}

Washington

4.60

USC

2.96

UCB

$-4.18$

Oregon State

$-5.96$

Big West

Fresno State

San Jose State

Arkansas

$-2.98$

New Mexico State

$-6.12$ 
Table 3 (continued)

\begin{tabular}{|c|c|c|}
\hline Conference & $\begin{array}{c}\text { \# of standard } \\
\text { deviations record } \\
\text { is over } .500^{a}\end{array}$ & $\begin{array}{c}\text { Conference } \\
\text { competitive } \\
\text { balance indicator }^{b}\end{array}$ \\
\hline
\end{tabular}

Southeastern Conf.

4.00

Florida

6.59

Tennessee

5.92

Kentucky

$-5.35$

Vanderbilt

$-7.78$

Southwestern Conf.

Texas A\&M

Arkansas

2.72

Rice $\quad-3.58$

Southern Meth $\quad-4.30$

WAC

BYU

Air Force

New Mexico

$-4.46$

UT El Paso

$-4.94$

Weighted average

${ }^{a}$ Based on assumption of equal playing strengths. ${ }^{b}$ Actual/ideal standard deviation. Based on conference-only play, cumulative records 1985-2001, and excludes ties.

$31 \%$ of team records are this imbalanced. Judging by these measures, then, persistent dominance and weakness among the teams is about as much a characteristic of college football as it is of professional sports. ${ }^{4}$

\section{Conclusions}

To date, research on the role of player pay in competitive-balance outcomes in college football has been theoretically and empirically unclear. Understanding this relationship is important insofar as it pertains to the justification for player pay restrictions - restrictions that are becoming more severe as the revenue that players generate increases. Understanding the determinants of competitive balance is important, too, because it influences the issue of how fairly the increasing financial gains (and losses) in college football are distributed among teams. Evidence indicates that a school's revenue from football is related to the school's ability to win football games (Padilla \& Baumer, 1994); a persistent lack of competitive balance suggests an unequal, and possibly unfair, division of the gains from college football across different schools. 
In an era of rising financial rewards for select college athletic departments, assessing the effectiveness and fairness of existing institutions in distributing these gains is important. Rising football revenue (either actual or potential) has fostered rapid increases in expenditures on football facilities and coaches' salaries (Sokolove, 2002; Witosky, 2002). Paradoxically, however, this also coincides with decreases in the share of revenue going to the players themselves.

Unlike professional sports, the degree of imbalance in college football has received surprisingly little attention. Do competitive-balance concerns help justify restrictions on player pay? Do they contribute to leveling the playing field? This study reveals that college football play departs substantially from an ideal of complete competitive balance on the field. Even if it were the case that restrictions on player compensation do, ceteris paribus, improve balance, then, clearly, this alone is hardly sufficient to bring about a reasonable amount of balance within (and among) college conferences. To the contrary, however, the findings here support the position that restrictions on player pay-analogous to a salary cap in professional sports-have had no effect on college football's competitive balance.

The coincidence of rising (and more uneven) financial rewards in college football (Fort, 2003; Zimbalist, 1999) with increased restrictions on player compensation raises important questions of fairness in the distribution of financial gains from college football that accrues to the athletes. For this reason it is important to understand the role of the NCAA in ameliorating or contributing to the persistence of competitive imbalance in college football. It could be that the redistribution inherent in NCAA player-compensation rules alone is sufficient justification for NCAA regulations: these rules do provide additional resources for college athletic programs, and they might add to fans' enjoyment of the game. That they are necessary for balance on the field, however, thus far remains an unsubstantiated claim.

A possible future inquiry could examine the determinants of competitive balance among different college football conferences. Such a study would quantify the importance of player pay vis-à-vis factors such as a school's winning tradition, coach's salary, location of the school, money spent on facilities, academic standards, and so forth. This would allow identification of the factors most important to greater balance, and, thus, the NCAA policies that would best remedy competitive imbalances in college football. With the increasing monetary gains (and losses) associated with college football, the importance of balance among schools in fielding competitive teams has increased significantly.

\section{Acknowledgments}

Particular thanks to Steven Walters, Ajufenn, Nancy Burnett, Dave Corbett, and Norm Arkans, seminar participants at the 2002 Western Economics Association meetings in Seattle, and two anonymous reviewers. 


\section{References}

Becker, G. (1985, September 30). College athletes should get paid what they are worth. Business Week, 18.

Bennett, R., \& J. Fizel. (1995). Telecast deregulation and competitive balance. American Journal of Economics and Sociology, 54, 183-199.

Brown, R. (1993). An estimate of the rent generated by a premium college football player. Economic Inquiry, 31, 671-684.

Brown, R. (1994). Measuring cartel rents in the college basketball player recruitment market. Applied Economics, 26, 27-34.

Butler, M. (1995). Competitive balance in Major League Baseball. American Economist, 39(2), 46-52.

Byers, W. (1995). Unsportsmanlike conduct. Ann Arbor: University of Michigan Press.

Depken, C. (1999). Free-agency and the competitiveness of Major League Baseball. Review of Industrial Organization, 14, 205-217.

Depken, C., \& Wilson, R. (2002). The impacts of cartel enforcement in NCAA Division $1 A$ football. Unpublished manuscript.

Eckard, W. (1998). The NCAA cartel and competitive balance in college football. Review of Industrial Organization, 13, 347-369.

Fleisher, A., Goff, B., \& Tollison, R. (1990). The NCAA: A study in cartel behavior. Chicago: University of Chicago Press.

Fort, R. (2003). Sports economics. Upper Saddle River, NJ: Prentice Hall.

Fort, R., \& Quirk, J. (1999). The college football industry. In J. Fizel, D. Gustafson, \& H. Hadley (Eds.), Sports economics. Westport, CT: Praeger.

Koch, J. (1983). Intercollegiate athletics. Social Science Quarterly, 64(2), 360-374.

Lee, Y., \& Fort, R. (2002). Time series analysis of structural change: Competitive balance in Major League Baseball. Unpublished manuscript.

Leonard, J., \& Prinzinger, J. (1984). An investigation into the monopsonistic market structure of division one NCAA football and its effect on college football players. Eastern Economic Journal, 10, 455-467.

Maxcy, J. (2002). Rethinking restrictions on player mobility in Major League Baseball. Contemporary Economic Policy, 20(2), 145-159.

NCAA. (2002). 2202-2003 NCAA Division I manual [electronic version]. Shawnee Mission, KA: NCAA.

Noll, R. (1991). The economics of intercollegiate sports. In J. Andre \& D. James (Eds.), Rethinking college athletics. Philadelphia: Temple University Press.

Padilla, A., \& Baumer, D. (1994). Big-time college sports. Journal of Sport and Social Issues, 18, 123-143.

Quirk, J., \& Fort, R. (1997). Pay dirt. Princeton, NJ: Princeton University Press.

Rottenberg, S. (1956). The baseball players' labor market. Journal of Political Economy, 64, 253-256.

Scully, G. (1989). The business of Major League Baseball. Chicago: University of Chicago Press.

Sheehan, R. (2000). The professionalization of college sports. In J. Losco \& B. Fife (Eds.), Higher education in transition. Westport, CT: Bergin \& Garvey.

Sokolove, M. (2002, December 22). How football can crush a college. New York Times Magazine, p. 36.

Suggs, W. (2002, November 29). How gears turn at a sports factory. Chronicle of Higher Education, p. A32. 
Sutter, D., \& Winkler, S. (2003). NCAA scholarship limits and competitive balance in college football. Journal of Sports Economics, 4, 3-18.

Szymanski, S. (2001). Income inequality, competitive balance and the attractiveness of team sports. The Economic Journal, 111, F69-F84.

Witosky, S. (2002, December 4). Coaches, programs prosper. Seattle Times.

Zimbalist, A. (1999). Unpaid professionals. Princeton, NJ: Princeton University Press.

\section{Notes}

${ }^{1}$ Quoted in The NCAA News Comment (March 27, 2000), available at www.ncaa.com

${ }^{2}$ An example of the Rottenberg invariance principle is that the introduction of competitive labor markets in professional sports ("free agency") has not corresponded with declines in competitive balance (Butler, 1995; Maxcy, 2002).

${ }^{3}$ The calculations are based on compensation if all players were in-state residents. Going back farther in time also reveals a steady decline in the percent of total football revenue at the University of Washington used to compensate athletes (P. King, personal communication, December 23, 2002).

${ }^{4}$ For college football, these indicators are based on, at most, 17 years of play; for professional sports, Quirk and Fort calculate them based on lifetime play. Examining college football teams' lifetime records might well reveal an even larger percentage of team records falling within the extreme tails of a normal distribution. If so, perpetual dominance and weakness among teams might be even more characteristic of college football than of professional sports. 